\title{
Subclinical Atherosclerosis in Patients with Prior Pulmonary Thromboembolism
}

\author{
Zafer Buyukterzi ${ }^{\mathrm{a}} \quad$ Meral Buyukterzi $^{\mathrm{b}} \quad$ Ercan Kurtipek $^{\mathrm{c}}$ \\ Mehmet Sertac Alpaydin ${ }^{a}$ Sukru Karaarslan ${ }^{a}$ \\ Departments of a Cardiology, ${ }^{b}$ Radiology, and ${ }^{c}$ Chest Diseases, Konya Training and Research Hospital, Konya, Turkey
}

\section{Significance of the Study}

- In this study, patients with a prior history of pulmonary thromboembolism (PTE) who lacked major cardiovascular risk factors such as hypertension, diabetes mellitus, hyperlipidemia, or smoking had a higher prevalence of subclinical atherosclerosis, reflected with greater carotid intima-media thickness when compared to healthy control subjects. Therefore, PTE patients without major cardiovascular risk factors should be closely monitored in order to avoid manifest atherosclerotic vascular disease and its unfavorable outcomes.

\section{Keywords}

Pulmonary thromboembolism - Subclinical atherosclerosis . Carotid intima-media thickness

\section{Abstract}

Objective: Recent studies have indicated that endothelial dysfunction is common in patients with a prior history of pulmonary thromboembolism (PTE). Based on the established relationship between endothelial dysfunction and atherosclerosis, we aimed to investigate carotid intima-media thickness (CIMT) as a marker of subclinical atherosclerosis in patients who have a prior history of PTE. Subjects and Methods: Medical records belonging to patients with a history of PTE and age- and gender-matched control subjects among those who underwent transthoracic echocardiography in Konya Training and Research Hospital were reviewed. Echocardiographic findings and cIMT measurements were recorded.
\end{abstract}

cIMT measurements were compared between patient and control groups, and then independent correlates of cIMT were investigated using appropriate statistical methods. Results: A total of 110 patients ( $64.02 \pm 12.67$ years, males: $n=$ 79 [71.81\%]; females: $n=31$ [28.19\%]) were found to be eligible for assessment. Of these patients, $55(50.00 \%)$ had a history of PTE. Patients with a history of PTE had significantly greater CIMT $(p=0.040)$. In this group of patients, CIMT positively and significantly correlated with basal right ventricular (RV) diameter $(r=0.271, p=0.022)$, RV diastolic area $(r=0.376$, $p=0.002)$, and systolic pulmonary artery pressure $(r=0.248$, $p=0.037)$. In the multivariate linear regression analysis, only RV diastolic area was independently associated with cIMT in patients with PTE $(p=0.010)$. Conclusion: Patients with a history of PTE have increased cIMT when compared to healthy subjects, and cIMT, which is a marker of subclinical atherosclerosis, is independently associated with RV diameter in these patients.

(c) 2017 S. Karger AG, Basel

\section{KARGER}

E-Mail karger@karger.com www.karger.com/mpp
(C) 2017 S. Karger AG, Basel

Karger

This is an Open Access article licensed under the terms of the Creative Commons Attribution-NonCommercial 3.0 Unported license (CC BY-NC) (www.karger.com/OA-license), applicable to the online version of the article only. Distribution permitted for non-commercial purposes only.
Zafer Buyukterzi, MD

Department of Cardiology

Konya Training and Research Hospital

TR-42090 Konya, Meram (Turkey)

E-Mail buyukterzizafer@ hotmail.com 


\section{Introduction}

Pulmonary thromboembolism (PTE) is a disease with high mortality rates that occurs as a result of the blockage of the pulmonary artery or its branches with a thrombus or embolus that develops in the systemic veins [1]. Pulmonary hypertension following an event of PTE, namely chronic thromboembolic pulmonary hypertension, which occurs as a result of obstructive pulmonary arterial remodeling due to major vessel thromboembolism, has been reported with a cumulative incidence of 0.1$9.1 \%$ within the first 2 years after a symptomatic pulmonary embolism event [2]. Recent data has indicated that endothelial dysfunction is common in patients with a prior history of PTE [3]. Based on the established relationship between endothelial dysfunction and atherosclerosis [4], we aimed to investigate carotid intima-media thickness (cIMT) as a marker of subclinical atherosclerosis in patients who have a prior history of PTE.

\section{Subjects and Methods}

Study Population

Medical records belonging to patients with a history of PTE and age- and gender-matched control subjects among those who underwent transthoracic echocardiography in Konya Training and Research Hospital were reviewed. Exclusion criteria were a previous history of coronary artery disease and major risk factors for coronary artery disease such as hypertension, diabetes mellitus, hyperlipidemia, and smoking. Fifty-five patients with a history of PTE and 55 without a history of PTE (control subjects) were included in the analysis. Detailed medical history, laboratory, and physical examination findings were included in the analysis. cIMT measurements were obtained during routine transthoracic echocardiography in all patients as a part of clinical care. The study protocol was approved by the Institutional Review Board.

\section{Transthoracic Echocardiography}

Assessment of systolic pulmonary artery pressure (sPAP) was carried out by measuring the maximal tricuspid regurgitation velocity and applying the modified Bernoulli equation to convert this value into pressure values. Estimated right atrial pressure was added to the obtained value [5]. The right ventricular (RV) dimensions were measured in accordance with recent guidelines [5].

\section{Evaluation of Carotid Intima-Media Thickness}

A Philips EPIQ 7c cardiology ultrasound machine (Andover, MA, USA) was used for cIMT measurements. Measurements were done while the patient was in the supine position and had the neck rotated to the contralateral side for ultrasonographic examination. Ultrasound images of the distal $1 \mathrm{~cm}$ of the far wall of each common carotid artery was obtained and mean cIMT values from the far walls of the right and left common carotid arteries (meanmean) were calculated [6]. Ultrasonographic measurements were performed by an expert sonographer who was blinded to the clinical data due to the retrospective nature of the study.
Med Princ Pract 2017;26:321-324

DOI: $10.1159 / 000475466$
Statistical Analysis

All analyses were performed using Statistical Package for the Social Sciences (SPSS) version 21.0 (SSPS Inc., Chicago, IL, USA). Normally distributed continuous variables were expressed as mean \pm standard deviation (SD) and skewed parameters as medians (25th-75th percentile). Categorical variables were expressed as percentages and compared using a $\chi^{2}$ test. Comparisons between 2 groups were made with the Student $t$ test and Mann-Whitney $\mathrm{U}$ test for continuous parameters with and without normal distribution, respectively. Correlation analysis was used to test univariate relations. Linear regression analysis model included age, body mass index, basal RV diameter, RV diastolic area, and sPAP to determine the independent associates of cIMT. A $p$ value of $<0.05$ was considered statistically significant.

\section{Results}

Medical records of a total of 110 patients $(64.02 \pm 12.67$ years, males: $n=79$ [71.81\%] females: $n=31$ [28.19\%]) who had undergone transthoracic echocardiography were retrieved from the medical records of Konya Training and Research Hospital. Of the 110 patients, 55 had a prior history of PTE and 55 patients were the age- and gender-matched control subjects. The average time interval between PTE episode and examination in the patient group was 3 years (2-5). Baseline characteristics of the study population are shown in Table 1 . Patients with a history of PTE had significantly greater cIMT than healthy controls $(0.87 \pm 0.23$ vs. $0.081 \pm 0.07 \mathrm{~cm}, p=0.040)$. They also had greater basal RV diameter ( $38.56 \pm 4.88$ vs. 27.37 $\pm 1.28 \mathrm{~mm}, p<0.001)$, RV diastolic area $(18.97 \pm 5.03 \mathrm{vs}$. $\left.13.76 \pm 1.63 \mathrm{~cm}^{2}, p<0.001\right)$, and $\operatorname{sPAP}(43.93 \pm 6.12 \mathrm{vs}$. $28.67 \pm 4.36 \mathrm{~mm} \mathrm{Hg}, p<0.001)$ when compared to the control group (Table 1). In the patient group, cIMT was positively and significantly correlated with basal RV diameter $(r=0.271, p=0.022)$, RV diastolic area $(r=0.376$, $p=0.002)$, and sPAP $(r=0.248, p=0.037)$. In the multivariate linear regression analysis, only RV diastolic area was independently associated with cIMT in patients with PTE $(p=0.010)$ (Table 2).

\section{Discussion}

In this study, patients with a prior history of PTE had increased cIMT when compared to healthy subjects. In addition, a significant correlation was detected between echocardiographic parameters and cIMT in patients with a prior history of PTE.

Previous studies have demonstrated that endothelial dysfunction and endothelium-dependent pathological
322

DOI: $10.1159 / 000475466$
Buyukterzi/Buyukterzi/Kurtipek/

Alpaydin/Karaarslan 
Table 1. Baseline characteristics of the study population $(n=110)$

\begin{tabular}{|c|c|c|c|c|}
\hline & $\begin{array}{l}\text { Patients with a } \\
\text { history of PTE }(n=55)\end{array}$ & $\begin{array}{l}\text { Patients without } \\
\text { history of PTE }(n=55)\end{array}$ & $\begin{array}{l}\text { Study population } \\
(n=110)\end{array}$ & $p$ value \\
\hline Age, years & $64.94 \pm 15.27$ & $63.18 \pm 9.76$ & $64.02 \pm 12.67$ & 0.408 \\
\hline \multicolumn{5}{|l|}{ Gender } \\
\hline Male, $n(\%)$ & $32(58.18)$ & $47(85.45)$ & $79(71.81)$ & 0.072 \\
\hline Female, $n(\%)$ & $23(41.82)$ & $8(14.55)$ & $31(28.19)$ & \\
\hline Body mass index & $30.65 \pm 3.60$ & $30.00 \pm 3.41$ & $30.31 \pm 3.50$ & 0.254 \\
\hline Carotid intima-media thickness, $\mathrm{cm}$ & $0.87 \pm 0.23$ & $0.81 \pm 0.07$ & $0.84 \pm 0.17$ & 0.040 \\
\hline Neutrophil count, $\times 10^{3} / \mu \mathrm{L}$ & $7.39(5.26-9.87)$ & $4.19(3.31-5.63)$ & $5.71(4.10-7.98)$ & $<0.001$ \\
\hline Lymphocyte count, $\times 10^{3} / \mu \mathrm{L}$ & $1.6(1.20-2.44)$ & $2.10(1.87-2.62)$ & $1.95(1.44-2.48)$ & 0.855 \\
\hline Serum creatinine, $\mathrm{mg} / \mathrm{dL}$ & $0.98(0.95-1.06)$ & $1.00(0.95-1.07)$ & $1.00(0.95-1.06)$ & 0.650 \\
\hline Left ventricular end-diastolic diameter, $\mathrm{mm}$ & $45.86 \pm 4.49$ & $45.85 \pm 4.74$ & $45.85 \pm 4.57$ & 0.988 \\
\hline Left ventricular ejection fraction, $\%$ & $61.99 \pm 4.77$ & $62.72 \pm 4.56$ & $62.37 \pm 4.66$ & 0.340 \\
\hline Basal right ventricle diameter, $\mathrm{mm}$ & $38.56 \pm 4.88$ & $27.37 \pm 1.28$ & $32.70 \pm 6.60$ & $<0.001$ \\
\hline Right ventricular diastolic area, $\mathrm{cm}^{2}$ & $18.97 \pm 5.03$ & $13.76 \pm 1.63$ & $16.09 \pm 4.41$ & $<0.001$ \\
\hline Systolic pulmonary artery pressure, $\mathrm{mm} \mathrm{Hg}$ & $43.93 \pm 6.12$ & $28.67 \pm 4.36$ & $35.94 \pm 9.28$ & $<0.001$ \\
\hline
\end{tabular}

PTE, pulmonary thromboembolism.

Table 2. Linear regression analysis to determine independent associates of carotid intima-media thickness in patients with a history of pulmonary thromboembolism $(n=55)$

\begin{tabular}{|c|c|c|c|c|c|c|c|c|c|c|}
\hline \multirow[t]{3}{*}{ Variable } & \multicolumn{5}{|c|}{ Univariate model } & \multicolumn{5}{|c|}{ Multivariate model } \\
\hline & \multicolumn{2}{|c|}{$\begin{array}{l}\text { unstandardized } \\
\text { coefficients }\end{array}$} & \multirow[t]{2}{*}{$p$ value } & \multicolumn{2}{|c|}{$\begin{array}{l}95.0 \% \text { confidence } \\
\text { interval for B }\end{array}$} & \multicolumn{2}{|c|}{$\begin{array}{l}\text { unstandardized } \\
\text { coefficients }\end{array}$} & \multirow[t]{2}{*}{$p$ value } & \multicolumn{2}{|c|}{$\begin{array}{l}95.0 \% \text { confidence } \\
\text { interval for B }\end{array}$} \\
\hline & B & $\begin{array}{l}\text { std. } \\
\text { error }\end{array}$ & & $\begin{array}{l}\text { lower } \\
\text { bound }\end{array}$ & $\begin{array}{l}\text { upper } \\
\text { bound }\end{array}$ & B & $\begin{array}{l}\text { std. } \\
\text { error }\end{array}$ & & $\begin{array}{l}\text { lower } \\
\text { bound }\end{array}$ & $\begin{array}{l}\text { upper } \\
\text { bound }\end{array}$ \\
\hline Age (years) & 0.005 & 0.002 & 0.010 & 0.001 & 0.008 & 0.003 & 0.002 & 0.056 & 0.000 & 0.007 \\
\hline $\mathrm{BMI}$ & 0.008 & 0.008 & 0.310 & -0.008 & 0.023 & - & - & - & - & - \\
\hline $\mathrm{RVd}(\mathrm{mm})$ & 0.014 & 0.006 & 0.013 & 0.003 & 0.025 & 0.008 & 0.010 & 0.437 & -0.012 & 0.027 \\
\hline RVarea $\left(\mathrm{cm}^{2}\right)$ & 0.016 & 0.005 & 0.003 & 0.006 & 0.027 & 0.014 & 0.005 & 0.010 & 0.003 & 0.025 \\
\hline sPAP (mm Hg) & 0.012 & 0.005 & 0.013 & 0.003 & 0.021 & 0.005 & 0.005 & 0.321 & -0.005 & 0.014 \\
\hline Neutrophil count $\left(\times 10^{3} / \mu \mathrm{L}\right)$ & -0.002 & 0.002 & 0.515 & -0.006 & 0.003 & - & - & - & - & - \\
\hline Lymphocyte count $\left(\times 10^{3} / \mu \mathrm{L}\right)$ & -0.001 & 0.006 & 0.886 & -0.014 & 0.012 & - & - & - & - & - \\
\hline Serum creatinine $(\mathrm{mg} / \mathrm{dL})$ & 0.425 & 0.361 & 0.243 & -0.295 & 1.144 & - & - & - & - & - \\
\hline $\operatorname{LVEDD}(\mathrm{mm})$ & 0.005 & 0.006 & 0.456 & -0.008 & 0.017 & - & - & - & - & - \\
\hline $\operatorname{LVEF}(\%)$ & -0.003 & 0.006 & 0.598 & -0.015 & 0.009 & - & - & - & - & - \\
\hline
\end{tabular}

BMI, body mass index; LVEDD, left ventricular end-diastolic diameter; LVEF, left ventricular ejection fraction; RVarea, right ventricular diastolic area; RVd, basal right ventricle diameter; sPAP systolic pulmonary artery pressure.

pathways occur after PTE episodes. A previous study showed that the receptor for advanced glycation end products (RAGE) pathway had a role in the pathophysiology of chronic thromboembolic pulmonary hypertension [7]. Another study [8] demonstrated significantly higher levels of endocan, which has been reported to be associated with organ-specific inflammation and endothelium- dependent pathological disorders in patients with diagnosis of PTE when compared to controls. Prior in vitro and ex vivo experiments suggested that pulmonary artery endothelial cells (ECs) in pulmonary hypertensive diseases exhibited an unusual hyperproliferative potential with decreased susceptibility to apoptosis, indicating that dysfunctional ECs may contribute to the progression of the 
diseases [9]. Circulating ECs, regarded as markers of endothelial damage, were found to be correlated with markers of endothelial function, such as flow-mediated dilation, von Willebrand factor, and tissue plasminogen activator levels [10]. Endothelial damage, which is a well-established response to cardiovascular risk factors and precedes the development of atherosclerosis, may be a possible explanation for the pathophysiological process underlying cIMT increase in PTE patients in our study since cIMT is a marker of subclinical atherosclerosis [4].

Elevated levels of anticardiolipin antibodies [11], endothelial factor VIII $[12,13]$, monocyte chemoattractant protein 1 [14], and endothelins $[15,16]$ have been found to be elevated in PTE. In a study that included 38 patients with PTE and 38 age- and gender- matched healthy subjects without risk factors for pulmonary embolism, levels of asymmetric dimethylarginine, TNF- $\alpha$, total antioxidant status, total oxidant status, and oxidative stress index showed a significant difference between the patient and control groups [17]. These findings suggest that patients with PTE have the triggering inflammatory and oxidative status for atherosclerosis initiation and development, which is consistent with the results of our study revealing increased cIMT in PTE patients.
Our study also revealed that cIMT was independently associated with RV diastolic area in patients with PTE. In a previous study, Guzel et al. [8] suggested that the serum endocan level, which has been reported to be associated with organ-specific inflammation and endothelium-dependent pathological disorders, correlated with RV dilation in PTE patients. When these two findings are considered together, RV dilation may be a marker for increased inflammatory activity and atherosclerotic risk in PTE patients but this conclusion needs to be verified in further studies.

\section{Conclusion}

Patients with a history of PTE have higher cIMT compared to healthy subjects and cIMT is independently associated with RV diastolic area in these patients.

\section{Disclosure Statement}

The authors report no conflicts of interest.

\section{References}

1 Roy PM, Meyer G, Vielle B, et al: Appropriateness of diagnostic management and outcomes of suspected pulmonary embolism. Ann Int Med 2006;144:157-164.

2 Lang IM, Pesavento R, Bonderman D, et al: Risk factors and basic mechanisms of chronic thromboembolic pulmonary hypertension: a current understanding. Eur Resp J 2013;41: 462-468.

3 Kurtipek E, Büyükterzi Z, Büyükterzi M, et al: Endothelial dysfunction in patients with pulmonary thromboembolism: neutrophil to lymphocyte ratio and platelet to lymphocyte ratio. Clin Resp J 2017;11:78-82.

4 Davignon J, Ganz P: Role of endothelial dysfunction in atherosclerosis. Circulation 2004; 109:27-32.

5 Rudski LG, Lai WW, Afilalo J, et al: Guidelines for the echocardiographic assessment of the right heart in adults: a report from the American Society of Echocardiography endorsed by the European Association of Echocardiography, a registered branch of the European Society of Cardiology, and the Canadian Society of Echocardiography. J Am Soc Echocardiogr 2010;23:685-713.
6 Stein JH, Korcarz CE, Hurst RT, et al: Use of carotid ultrasound to identify subclinical vascular disease and evaluate cardiovascular disease risk: a consensus statement from the American Society of Echocardiography Carotid Intima-Media Thickness Task Force. Endorsed by the Society for Vascular Medicine. J Am Soc Echocardiogr 2008;21:93-111.

7 Moser B, Megerle A, Bekos C, et al: Local and systemic RAGE axis changes in pulmonary hypertension: CTEPH and iPAH. PloS One 2014;9:e106440.

8 Guzel A, Duran L, Köksal N, et al: Evaluation of serum endothelial cell specific molecule-1 (endocan) levels as a biomarker in patients with pulmonary thromboembolism. Blood Coag Fibrinolysis 2014;25:272-276.

9 Sakao S, Tatsumi K: Crosstalk between endothelial cell and thrombus in chronic thromboembolic pulmonary hypertension: perspective. Histol Histopathol 2013;28:185-193.

10 Boos CJ, Blann AD, Lip GY: Assessment of endothelial damage/dysfunction: a focus on circulating endothelial cells. Methods Mol Med 2007;139:211-224.

11 Konstantinides SV, Torbicki A, Agnelli G, et al: 2014 ESC guidelines on the diagnosis and management of acute pulmonary embolism. Eur Heart J 2014;35:3033-3069.
12 Wolf M, Boyer-Neumann C, Parent F, et al: Thrombotic risk factors in pulmonary hypertension. Eur Resp J 2000;15:395-399.

13 Bonderman D, Turecek PL, Jakowitsch J, et al: High prevalence of elevated clotting factor VIII in chronic thromboembolic pulmonary hypertension. Thromb Haemost 2003;90: 372-376.

14 Kimura $\mathrm{H}$, Okada $\mathrm{O}$, Tanabe $\mathrm{N}$, et al: Plasma monocyte chemoattractant protein-1 and pulmonary vascular resistance in chronic thromboembolic pulmonary hypertension. Am J Resp Crit Care Med 2001;164:319-324.

15 Reesink HJ, Meijer RC, Lutter R, et al: Hemodynamic and clinical correlates of endothelin-1 in chronic thromboembolic pulmonary hypertension. Circ J 2006;70:1058-1063.

16 Sofia M, Faraone S, Alifano M, et al: Endothelin abnormalities in patients with pulmonary embolism. Chest 1997;111:544-549.

17 Halici B, Sarinc Ulasli S, Günay E, et al: Assessment of inflammatory biomarkers and oxidative stress in pulmonary thromboembolism: follow-up results. Inflammation 2014; 37:1186-1190. 